\title{
Antioxidant properties of some common oyster mushrooms grown in North East India
}

\author{
AFROZ MANSURI ${ }^{1}$, DILIP KUMAR SARMAH ${ }^{2 *}$ and ANANTA SAIKIA ${ }^{3}$ \\ ${ }^{1}$ Central Bank of India, Talep Branch, Tinsukia 786 156, Assam, India \\ ${ }^{2}$ Department of Plant Pathology, ${ }^{3}$ Department of Horticulture, Assam Agricultural University, Jorhat 785 013 , Assam, India
}

Received: 05 December 2016/ Accepted: 20 February 2017/ Published online: 23 March 2017

(c) Indian Phytopathological Society 2017

\begin{abstract}
Six oyster mushrooms, viz., Pleurotus ostreatus (Jacq. ex Fr.) P. Kumm., P. sapidus (Schulz.) Sacc., $P$. djamor (Rumph.) Boedijn, P. florida (Mont.) Singer, $P$. sajor-caju (Fr.) Singer and $P$. citrinopileatus Singer were evaluated for their antioxidant properties. The antioxidant activity was more in pink coloured species (the highest in $P$. djamor, followed by $P$. ostreatus, and grey mushroom $P$. sajor-caju) than the white species ( $P$. florida, $P$. sapidus and $P$. citrinopileatus), which established the positive effect of fruiting body pigmentation on antioxidant properties. A strong correlation between phenolic content and antioxidant activity was observed for all the species investigated. $P$. citrinopileatus showed higher chelating and radical scavenging effects than $P$. florida though it contained lower amount of phenol than $P$. florida. The investigation revealed the antioxidative potential of the pigmented mushrooms, viz., $P$. djamor and $P$. ostreatus. These species, enriched with beneficial bioactive components, have much potential for inclusion in breeding programmes and should be popularized for cultivation purpose.
\end{abstract}

Keywords: Antioxidant activity, mushroom, oyster mushroom, pigmented mushroom

Mushrooms are becoming increasingly popular and often find a place in human diets, because of their established nutritional and medicinal properties (Thakur, 2014; Jedinak et al., 2010). Oyster mushroom (Pleurotus spp.) is widely cultivated for edible purpose and popular among farmers for its wide adaptability (Gogavekar et al., 2014). Although, about 40 species of oyster mushroom have been recognized and documented scientifically, only 12 species are being cultivated in different parts of India, which perform well in various types of lignocellulosic materials degrading lignin efficiently (Dehariya and Vyas, 2013). Production of oyster mushroom in India is estimated to be $15-20,000$ metric tonnes annually (Thakur, 2014). Low cost production technology is available for cultivation of this mushroom. Various species of Pleurotus have different temperature requirement for growth and development which makes them ideally suited for cultivation throughout the year in various regions of India.

Besides, being rich sources of nutrients with high food value, mushrooms contain many biologically active compounds of medicinal importance (Khatun et al., 2015). Free radical formation is associated with normal metabolism in our body during consumption of oxygen leading to the generation of a series of oxygen radical (Kozarski et al., 2015), which interact with biological system causing several diseases. Mushrooms are rich in natural antioxidants which increase the anti-oxidative

${ }^{*}$ Corresponding author: sarmah.dilip@ gmail.com capacity of plasma and reduce risk of certain diseases like cancer, heart diseases, cirrhosis, atherosclerosis etc. (Kozarski et al., 2015). Consumption of oyster mushroom extract aids in protecting major organs like liver, heart and brain from oxidative damage (Jayakumar et al., 2006). Secondary metabolites, such as phenols and flavonoids from mushrooms, have been regarded as potent free radical scavengers (Visioli et al., 1998). They inhibit xanthine oxidase involved in catalysis of xanthine which may otherwise lead to accumulation of uric acid and cause gout (Zhou et al., 2001).

Forest belts of North Eastern region are very rich in microbial resources including macrofungi (Singh and Chhetri, 2010). Several species of oyster mushrooms have been cultivated in the region mostly for culinary purposes. Considering the limited information available on the oyster mushrooms of North East India, the present work was undertaken to investigate their anti-oxidative potentials.

\section{MATERIALS AND METHODS}

\section{Mushroom species}

Six mushroom species, viz., Pleurotus ostreatus (PO), $P$. sapidus (PS), P. djamor (PD), P. florida (PF), P. sajorcaju (PSC) and $P$. citrinopileatus (PC) were used for the investigation. The species were obtained from the culture collections maintained at the Department of Plant 
Pathology, Assam Agricultural University, Jorhat 785013, Assam; which were originally sourced from the National Research Centre for Mushroom, Solan (presently Directorate of Mushroom Research).

\section{Sample preparation}

Dried mushroom was made into fine powder by using an electric grinder and passing through a $250 \mathrm{~mm}$ sieve, packed in plastic bag and stored in refrigerator at $4^{\circ} \mathrm{C}$ until analysis. Preparation of extract was done as per the method described earlier with some modifications (Elmastas et al., 2007). About $25 \mathrm{~g}$ of dried mushroom sample was weighed and mixed with $60 \mathrm{ml}$ of $99 \%$ methanol in a $250 \mathrm{ml}$ conical flask and then put on a shaker at $150 \mathrm{rpm}$ for 24 hours at room temperature after sealing the mouth of the flask with DuraSeal ${ }^{\mathrm{TM}}$ film (Diversified Biotech, Boston). Whatman No. 42 filter paper was used to obtain the filtrate and the residue was reextracted under the same condition repeatedly until the extracts became colourless each time adding $60 \mathrm{ml}$ methanol to it. The filtrates were combined together and the methanol was removed using an IKA RV10 rotary vacuum evaporator (IKA India Private Limited, Bangalore, India) at $40^{\circ} \mathrm{C}$ to obtain the dry extracts of various mushroom samples. The extracts were placed in plastic bottles, flushed with nitrogen and stored at $40^{\circ} \mathrm{C}$ in a refrigerator.

\section{Radical scavenging activity (RSA)}

The free radical scavenging activity of mushroom in terms of ability to annihilate 1-diphenyl-2-picryl-hydrazil (DPPH) was measured (Blois, 1958). The stock solution was prepared by dissolving $0.1 \mathrm{~g}$ extract in $100 \mathrm{ml}$ methanol to obtain a concentration of $1 \mathrm{mg} / \mathrm{ml}$. Hundred $\mathrm{ml}$ of 0.1 $\mathrm{mM}$ solution of DPPH was prepared in methanol and 1 $\mathrm{ml}$ of this solution was added to $3 \mathrm{ml}$ of mushroom extracts with $180 \mu \mathrm{g} / \mathrm{ml}$ concentration. The mixture was shaken in a horizontal shaker and allowed to stand at room temperature for $30 \mathrm{~min}$. The absorbance of the reaction mixture was then measured in a Cary 50 UVVIS spectrophotometer (Agilent Technologies, Santa Clara, USA) at $517 \mathrm{~nm}$. The higher RSA was indicated by lower absorbance. The RSA was calculated using the following equation:

$\operatorname{RSA}(\%)=\frac{A_{0}-A_{1}}{A_{0}} \times 100$

Where, $A_{0}$ - Absorption of blank sample, $A_{1}$ - Absorption of tested solution

\section{Reducing power}

The reducing power of methanolic extract of mushroom was determined according to Oyaizu (1986) with some modifications. Methanolic extract of $200 \mu \mathrm{g} / \mathrm{ml}$ concentrations was prepared in methanol. The reaction mixture was prepared with $2.5 \mathrm{ml}$ of $0.2 \mathrm{M}$ phosphate buffer ( $\mathrm{pH} 6.6), 2.5 \mathrm{ml}$ of $1 \%$ potassium ferricyanide and the extract. The mixture was then incubated at $50^{\circ} \mathrm{C}$ for
20 minutes, cooled to room temperature, $2.5 \mathrm{ml}$ of $10 \%$ trichloroacetic acid added and finally centrifuged at $1000 \mathrm{~g}$ for $10 \mathrm{~min}$. Then, $2.5 \mathrm{ml}$ of distilled water, $0.5 \mathrm{ml}$ of $0.1 \%$ ferric chloride and $2.5 \mathrm{ml}$ of the supernatant were combined. The absorbance of the mixture was measured in a Cary 50 UV-Vis at $700 \mathrm{~nm}$.

\section{Chelating effect on ferrous ion}

The chelating effect on ferrous ions was estimated according to the method described by Dinis et al. (1994). From the stock solution prepared for estimation of RSA, $200 \mu \mathrm{g} / \mathrm{ml}$ concentration of methanolic extract of mushroom species was prepared in methanol, and then $0.05 \mathrm{ml}$ of $2 \mathrm{mM}$ ferrous chloride was added to each of the test tubes followed by addition of $0.2 \mathrm{ml}$ of $5 \mathrm{mM}$ ferrozine. The mixture was shaken vigorously in a horizontal shaker and allowed to stand for $10 \mathrm{~min}$ at room temperature. The absorbance was measured, once the mixture reached equilibrium after $10 \mathrm{~min}$, in a Cary 50 UV-VIS spectrophotometer at $562 \mathrm{~nm}$. The percentage of inhibition of ferrrozine- $\mathrm{Fe}^{2+}$ complex was measured by the formula:

Per cent inhibition $=\frac{A_{\text {blank }}-A_{\text {sample }}}{A_{\text {blank }}} \times 100$

\section{Total phenolics}

Dried powdered sample, about $0.5 \mathrm{~g}$ of each mushroom species, was weighed accurately and mixed with $5 \mathrm{ml}$ of $80 \%$ ethanol in a $100 \mathrm{ml}$ conical flask and put on a shaker for about $24 \mathrm{hrs}$ at $150 \mathrm{rpm}$ and then centrifuged at $10,000 \mathrm{rpm}$ for $10-15 \mathrm{~min}$. The supernatant was taken and evaporated to dryness on water bath and the residue was dissolved in a known volume of water for further analysis.

Total phenolic content was determined according to the method of Bray and Thorpe (1954) Aliquot (50 $\mu \mathrm{l})$ was taken out from each sample into test tubes and the volume was made up to $3 \mathrm{ml}$ by water. Then, $0.5 \mathrm{ml}$ of Folin-ciocalteau reagent was added and allowed to stand for three min. Then, $2 \mathrm{ml}$ of $20 \%$ sodium carbonate was added, thoroughly mixed and the test tubes were placed in boiling water for $1 \mathrm{~min}$, cooled and the absorbance measured in a Cary 50 UV-Vis spectrophotometer at 650 $\mathrm{nm}$ against a reagent blank. Catechol was used as standard during the analysis.

\section{Total flavonoid content}

Dried $0.5 \mathrm{~g}$ mushroom powder was mixed with $5 \mathrm{ml}$ of $80 \%$ ethanol in $100 \mathrm{ml}$ of conical flask and put on a shaker at $200 \mathrm{rpm}$ for $24 \mathrm{~h}$. The extracts were filtered through Whatman No. 42 filter paper. The volume of the filtrate was adjusted to $5 \mathrm{ml}$ with $80 \%$ ethanol and was used for further analysis.

The total flavonoid was determined according to Woisky and Salatino (1998) with minor modification. In a test tube, $1.5 \mathrm{ml} 95 \%$ ethanol, $0.1 \mathrm{ml}$ of $10 \%$ aluminium chloride, $0.1 \mathrm{ml}$ of $1 \mathrm{M}$ potassium acetate and $2.8 \mathrm{ml}$ of 


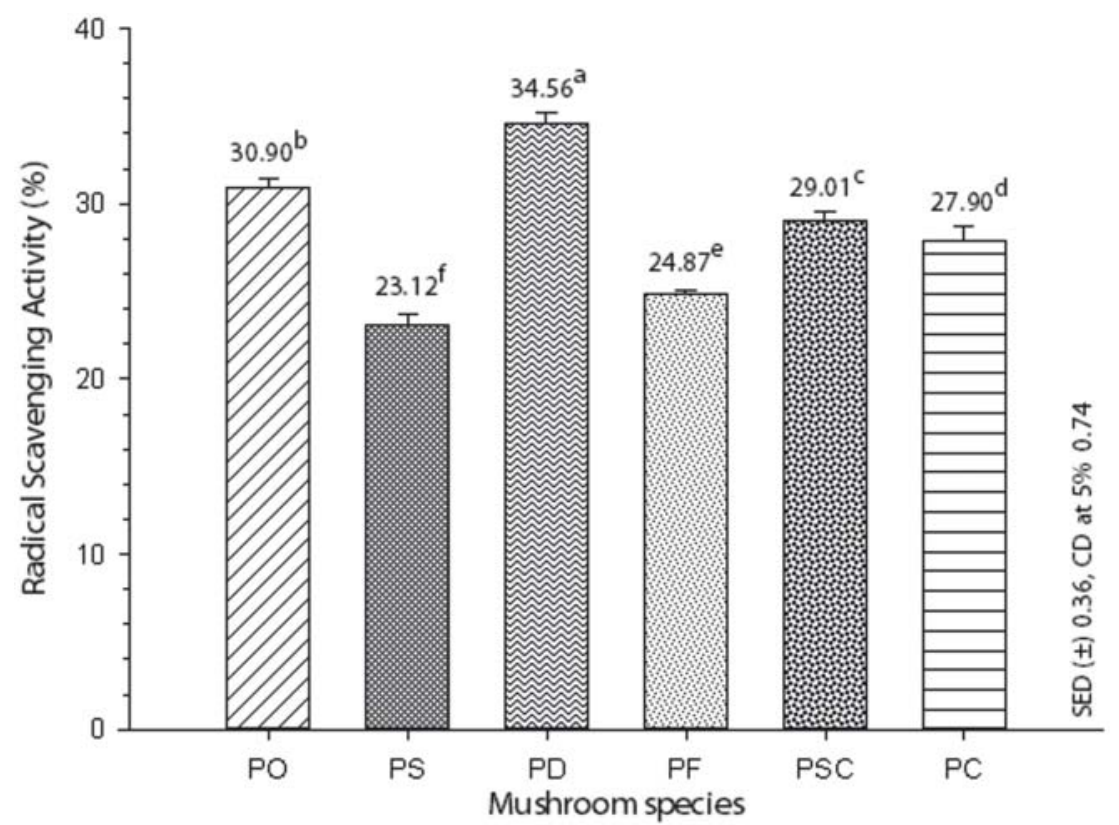

Fig. 1. Radical scavenging activity of the mushroom species

distilled water were added to $0.5 \mathrm{ml}$ of extract. After incubation for $30 \mathrm{~min}$ at room temperature, the absorbance was measured at $415 \mathrm{~nm}$ in a Cary 50 UVVis spectrophotometer. Standard was prepared by dissolving $10 \mathrm{mg}$ of quercetin in $100 \mathrm{ml}$ of $80 \%$ ethanol, whose final concentration was $100 \mu \mathrm{g} / \mathrm{ml}$.

\section{Statistical analysis}

CRD was employed for the statistical analysis of the data. The data collected were subject to statistical analysis by Fisher's method of analysis of variance. Significance of variance among the data was analysed by calculating the $\mathrm{F}$ value and comparing it with the tabulated value of "F" at $5 \%$ level of probability.

\section{RESULTS}

\section{Radical scavenging activity}

The comparison among the six oyster mushroom species for radical scavenging activity revealed that it was highest in $P$. djamor which was $34.56 \%$ followed by $P$. ostreatus, $P$. sajor-caju, P. citrinopileatus, $P$. florida and $P$. sapidus which were $30.90,29.01,27.90,24.87$ and $23.12 \%$ respectively at $180 \mu \mathrm{g} / \mathrm{ml}$ of mushroom extract (Fig. 1).

\section{Reducing power}

In our study, the highest reducing power was exhibited by $P$. djamor (0.51) followed by P. ostreatus, P. sajor-caju, $P$. florida, $P$. citrinopileatus and $P$. sapidus $(0.40,0.33$, $0.26,0.20$ and 0.16 respectively) at $200 \mu \mathrm{g} / \mathrm{ml}$ concentration of extract (Fig. 2).

The reducing power was measured in terms absorbance of various mushroom samples, higher the absorbance more is the reducing power.

\section{Chelating effect}

The chelating effect on ferrous ions was also highest in P. djamor (27.30\%) followed by P. ostreatus, P. sajor-caju, $P$. citrinopileatus, $P$. florida and $P$. sapidus $(24.61,21.05$, 20.39, 18.78 and $16.81 \%$ respectively) (Fig. 3).

\section{Total phenolics}

In the present study, the total phenolic content was highest in P. djamor (14.35mg catechol equivalent $/ \mathrm{g}$ ) with the lowest in P. sapidus (9.64mg) (Fig. 4). According to phenolic content, mushroom species are arranged in descending order: Pleurotus djamor $>P$. ostreatus $>P$. sajor-caju $>$ P. florida $>$ P. citrinopileatus $>P$. sapidus, respectively.

\section{Total flavonoids}

In the present investigation, the highest flavonoid was found in pink mushroom $P$. djamor $(2.85 \mathrm{mg}$ quercetin equivalent/g on dry weight basis) followed by P. ostreatus, grey $P$. sajor-caju, and white strains $P$. florida, $P$. citrinopileatus and $P$. sapidus (Fig. 5).

\section{DISCUSSION}

Several investigations for antioxidant activity have been conducted during the past decade in many fruits, vegetables, herbs, cereals, sprouts and seeds. Natural antioxidants are known to protect organisms and cells from damage by oxidative stress (Kozarski et al., 2015). Antioxidant capacity of plant tissue is closely associated with the activity of enzymes responsible for scavenging free radicals (Khatua et al., 2013). The radical scavenging activities of oyster mushroom are higher in mushrooms producing coloured fruits bodies. This was established in our study, as the highest radical scavenging activity 


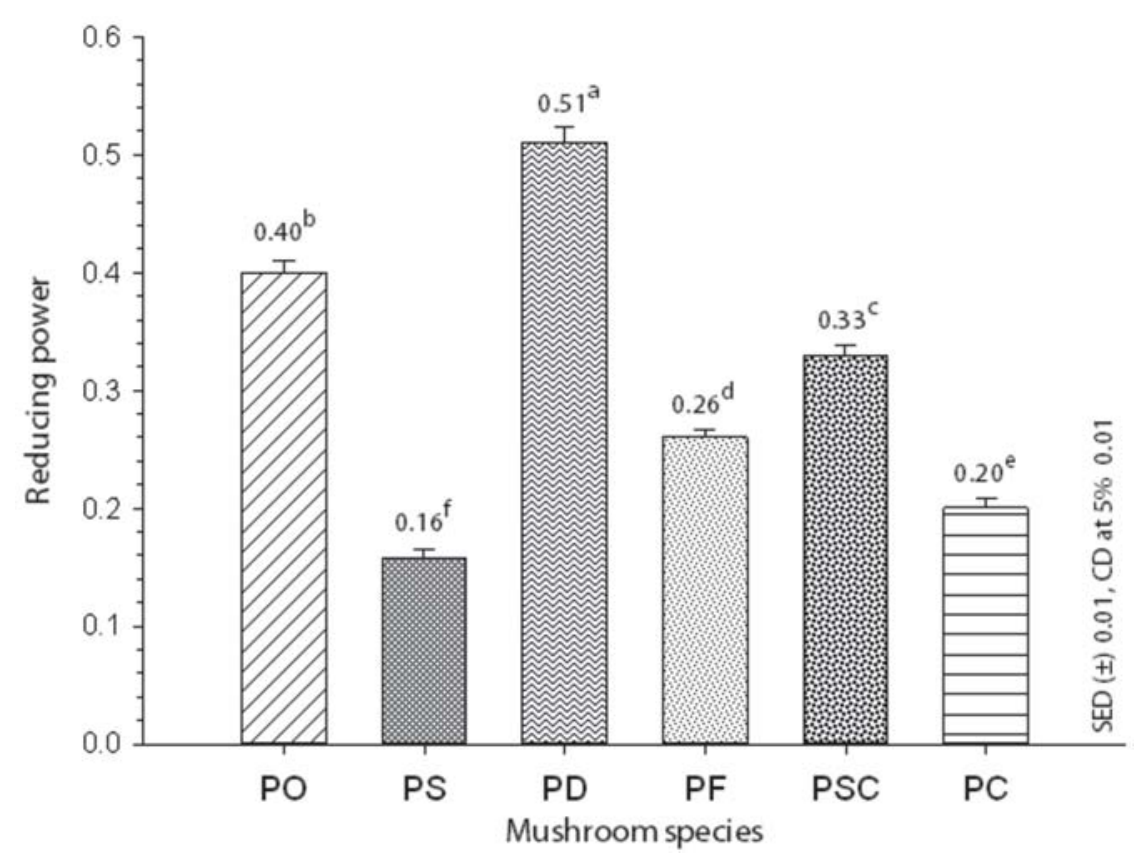

Fig. 2. Reducing power of the mushroom species

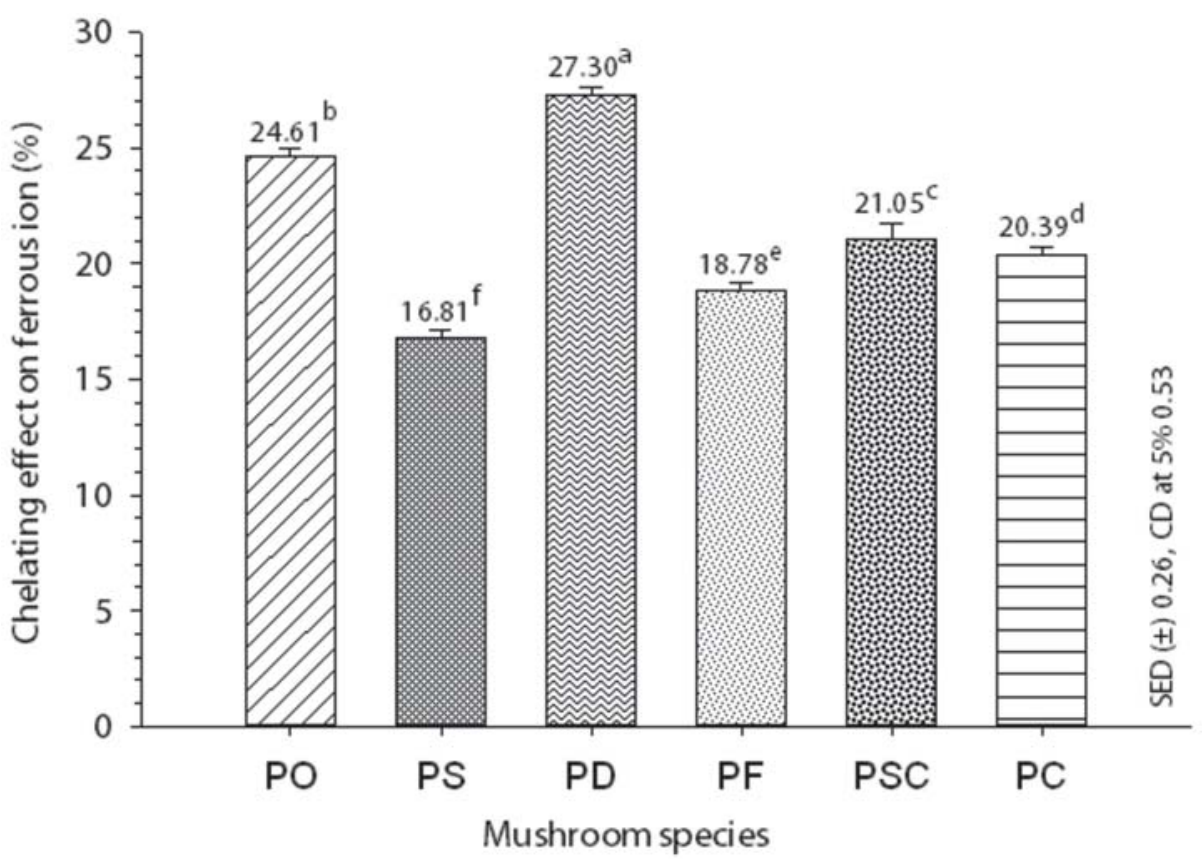

Fig. 3. Chelating effect of the mushroom species on ferrous ion

was found in pink mushroom P. djamor. The $30.90 \%$ RSA of $P$. ostreatus at $180 \mu \mathrm{g} / \mathrm{ml}$ concentration was lower on the basis of per cent inhibition. This shows that with the increase in concentration, the RSA in mushroom increases. Our result on $P$. ostreatus was higher than $29.0 \%$ at $2 \mathrm{mg} / \mathrm{ml}$ of concentration as reported by Kim et al. (2009). The results obtained for $P$. sajor-caju and $P$. florida were higher than the findings of Ramkumar et al. (2010), whereas for $P$. citrinopileatus, the result was at par with that of Lee et al. (2007), based on the concentration as discussed above for $P$. ostreatus. Although, the RSA of $P$. sapidus was the lowest among all the species under investigation, the finding has importance since no earlier report on this species was available elsewhere.

The reducing power of mushroom species is positively influenced by their hydrogen-donating ability (Khatua et al., 2013). This was true as higher reducing power was found in pigmented mushroom Pleurotus djamor. Therefore, pigmented mushroom might contain higher amount of reductants than other mushroom, which could terminate radical chain reaction reacting with free radicals (Ramkumar et al., 2010; Kim et al., 2009).

Phenolic compounds such as anthocyanins and carotenoids are free radical scavengers, due to their 


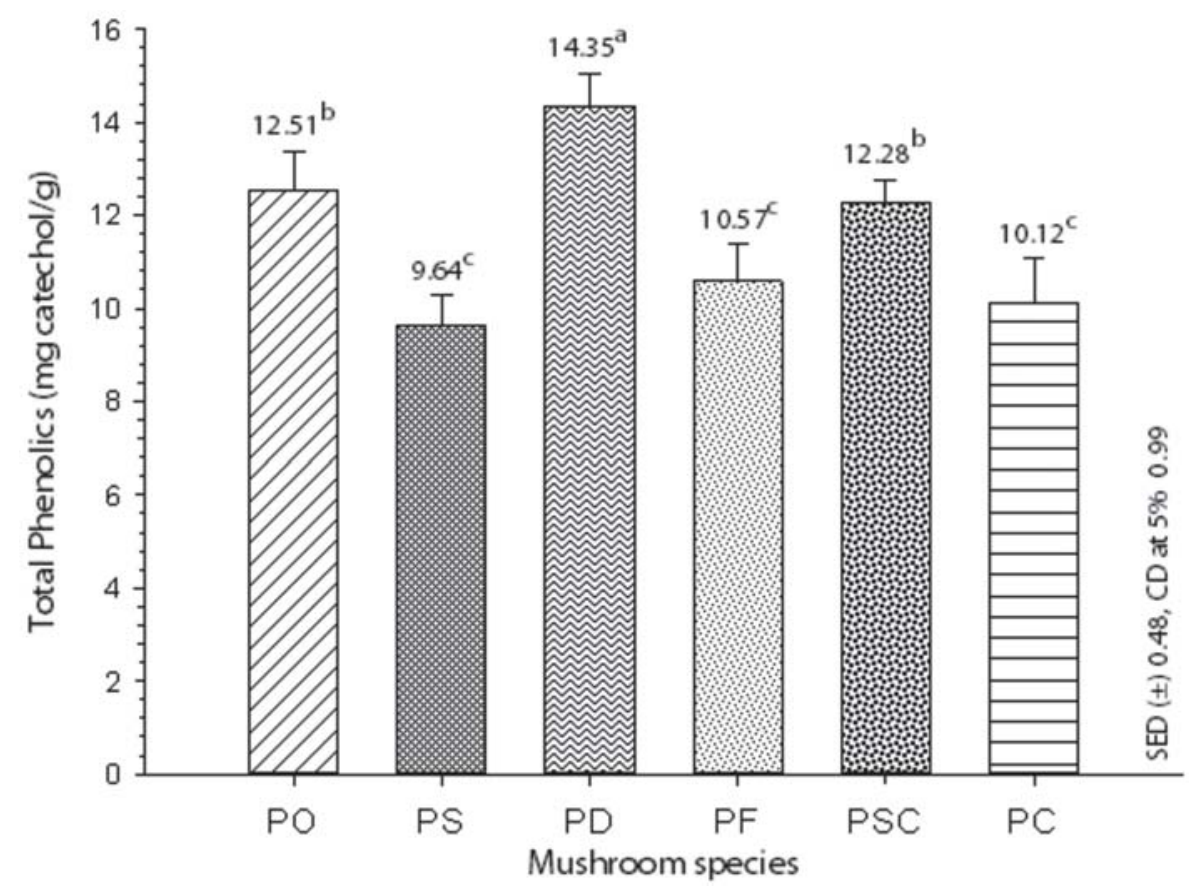

Fig. 4. Total phenolic content of the mushroom species

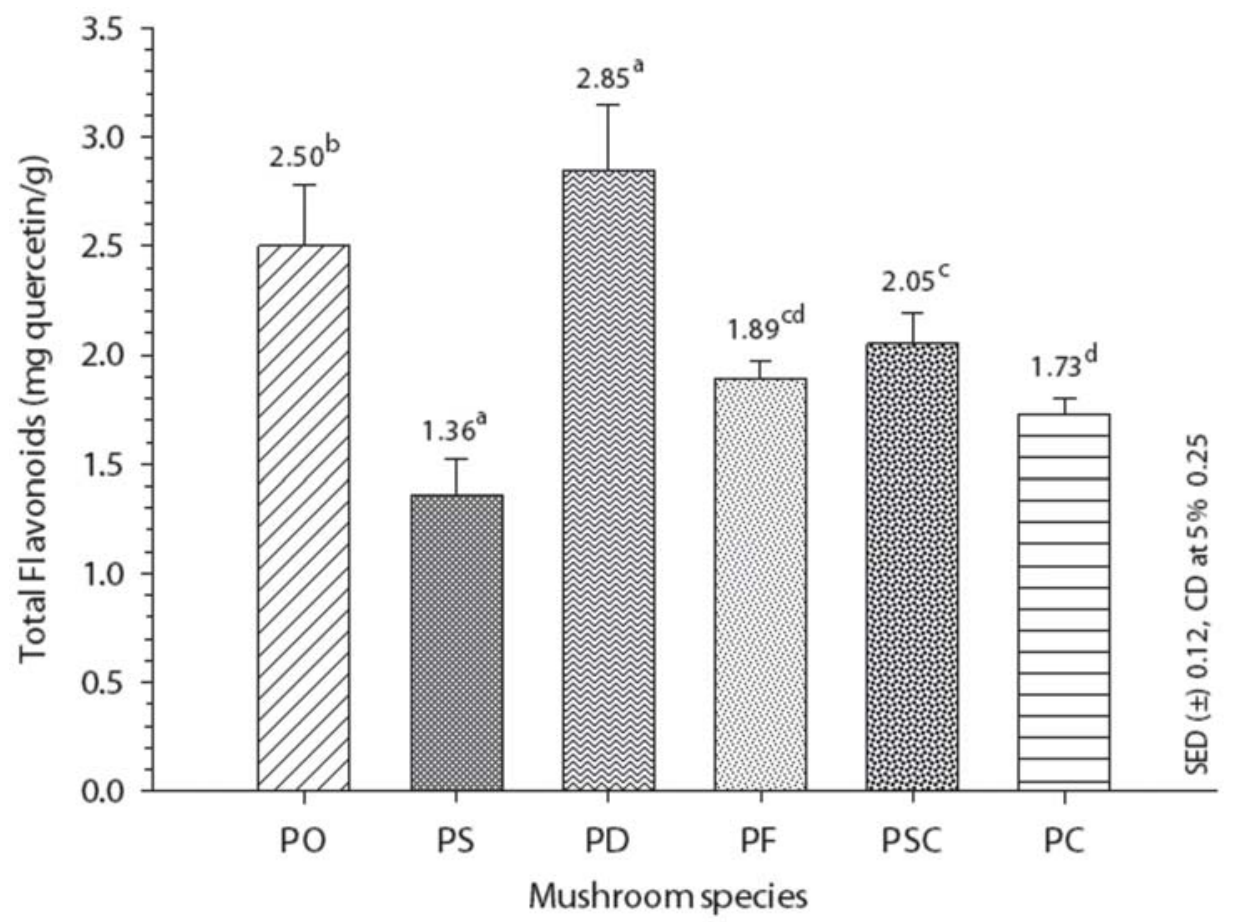

Fig. 5. Total flavonoid content of the mushroom species

ability to donate hydrogen atoms or electrons (Cui et al., 2013; Mazandarani et al., 2011). The variation in total phenolics in all the 6 oyster mushrooms under investigation manifested the differences in antioxidant activities of the mushrooms species in terms of radical scavenging, reducing power, and chelating effects. Earlier studies have established that the association of phenolic contents with their antioxidant activities due to their redox potentials allowing them to act as reducing agents or hydrogen donors (Kozarski et al., 2015). Similar results were reported earlier by Lee et al. (2007) in $P$. citrinopileatus.
There has been a growing interest in pigment components of natural food, belonging to flavonoid group, which may promote human health or lower the risk for disease. Deep pigmented fruits, vegetables or foods are recognized as healthier to human body (Lin and Tang, 2007). Similar results were also reported by earlier workers (Gogavekar et al., 2014; Sudha et al., 2012).

A correlation between total phenols and antioxidant property of mushroom has already been established (Turkoglu et al., 2007). According to our results, though $P$. citrinopileatus had lower amount of phenol than $P$. 
florida, it showed higher radical scavenging activity and chelating effect on ferrous ion than $P$. florida. Thus, it can be concluded that other factors might be involved for these properties. However, data in the literature about the relationship of phenolics and antioxidant activity are contradictory (Othman et al., 2007). While some authors had observed high correlation (Kozarski et al., 2015), others did not find any correlation with the antioxidant property (Othman et al., 2007), which might be attributed to other water and alcohol soluble nonphenolics compounds like tocopherols, $\beta$-carotene, ascorbic acid, selenium etc.

The investigation was a preliminary study on the antioxidant properties of some common edible oyster mushrooms of Assam. It was seen that $P$. djamor and $P$. ostreatus had high health-promoting antioxidant properties. Pigmented mushrooms have high amounts of phenolic compounds, and consequently have higher antioxidant and radical scavenging activity. Presently, white mushroom species like $P$. florida, $P$. sapidus and $P$. citrinopileatus, and grey species $P$. sajor-caju are commonly cultivated by farmers in Assam. Our investigation has revealed that the pigmented species like $P$. djamor and white species $P$. ostreatus are healthier than the other species, which should be popularized and brought into cultivation. These two species have the potential for their inclusion in a breeding programme for improvement of the species already in cultivation in Assam.

\section{REFERENCES}

Blois MS (1958). Antioxidant determinations by the use of a stable free radical. Nature 181: 1199-1200.

Bray HG and Thorpe WV (1954). Analysis of phenolic compounds of interest in metabolism. In: Methods of Biochemical Analysis, (Ed. Glick D ), John Wiley \& Sons, Inc., Hoboken, NJ, USA.

Chang ST, Wu JH, Wang SY, Kang PL, Yang NS and Shyur LF (2001). Antioxidant activity of extracts from Acacia confuse bark and heartwood. J. Agric. Food Chem. 49: 3420-3424.

Cui C, Zhang S, You L, Ren J, Luo W, Chen W and Zhao M (2013). Antioxidant capacity of anthocyanins from Rhodomyrtus tomentosa (Ait.) and identification of the major anthocyanins. Food Chem. 139: 1-8.

Dehariya P and Vyas D (2013). Effect of different agro-waste substrates and their combinations on the yield and biological efficiency of Pleurotus sajor-caju. IOSR J. Pharm. Biol. Sci. 8: 60-64.

Dinis TCP, Madeira VMC and Almeida LM (1994). Action of phenolic derivatives (acetaminophen, salicylate, and 5aminosalicylate) as inhibitors of membrane lipid peroxidation and as peroxyl radical scavengers. Arch. Biochem. Biophy. 315: 161-169.

Elmastaș M, Isildak O, Turkekul I and Temur N (2007). Determination of antioxidant activity and antioxidant compounds in wild edible mushrooms. J. Food Comp. Anal. 20: $337-345$

Gogavekar SS, Rokade SA, Ranveer RC, Ghosh JS, Kalyani DC and Sahoo AK (2014). Important nutritional constituents, flavour components, antioxidant and antibacterial properties of Pleurotus sajor-caju. J. Food Sci. Technol. 51: 1483-1491.
Jayakumar T, Ramesh E and Geraldine P (2006). Antioxidant activity of the oyster mushroom, Pleurotus ostreatus, on $\mathrm{CCl}_{4}$-induced liver injury in rats. Food Chem. Toxicol. 44: 1989-1996.

Jedinak A, Dudhgaonkar S, Jiang J, Sandusky G and Sliva D (2010). Pleurotus ostreatus inhibits colitis-related colon carcinogenesis in mice. Int. J. Mol. Med. 26: 643-650.

Khatua S, Paul S and Acharya K (2013). Mushroom as the potential source of new generation of antioxidant: A review. Res. J. Pharm. Tech. 6: 495-505.

Khatun S, Islam A, Cakilcioglu U, Guler P and Chatterjee NC (2015). Nutritional qualities and antioxidant activity of three edible oyster mushrooms (Pleurotus spp.). NJAS Wagening. J. Life Sci. 72-73: 1-5.

Kim JH, Kim SJ, Park HR, Choi JI, Ju YC, Nam KC, Kim SJ and Lee SC (2009). The different antioxidant and anticancer activities depending on the color of oyster mushrooms. J. Med. Plant Res. 3: 1016-1020.

Kozarski M, Klaus A, Jakovljevic D, Todorovic N, Vunduk J, Petroviæ P, Niksic M, Vrvic MM and Griensven LV (2015). Antioxidants of edible mushrooms. Mol. 20: 19489-19525.

Lee YL, Huang GW, Liang ZC and Mau JL (2007). Antioxidant properties of three extracts from Pleurotus citrinopileatus. LWT 40: 823-833.

Lin JY and Tang CY (2007). Determination of total phenolic and flavonoid contents in selected fruits and vegetables, as well as their stimulatory effects on mouse splenocyte proliferation. Food Chem. 101: 140-147.

Mazandarani M, Moghaddam PZ, Baiat H, Zolfaghari MR, Ghaemi EA and Hemati H (2011). Antioxidant activity, phenol, flavonoid and anthocyanin contents in various extracts of Onosma dichroanthum Boiss. in north of Iran. Iran. J. Plant Physiol. 1: 169-176.

Othman A, Ismail A, Ghani NA and Adenan I (2007). Antioxidant capacity and phenolic content of cocoa beans. Food Chem. 100: 523-1530.

Oyaizu M (1986). Studies on products of browning reaction: Antioxidantive activity of products of browning reaction prepared from glucosamine. Jpn. J. Nutr. 44: 307-315.

Ramkumar L, Ramanathan T, Thirunavukkarasu $\mathrm{P}$ and Arivuselvan N (2010). Antioxidant and radical scavenging activity of nine edible mushroom extract. Int. J. Pharmacol. 6: 950-953.

Singh MN and Chhetry GKN (2010). Biodiversity of macrofungi in Imphal, India-I. Indian Phytopath. 63: 79-82.

Sudha G, Vadivukkarasi S, Shree RBI and Lakshmanan P (2012). Antioxidant activity of various extracts from an edible mushroom Pleurotus eous. Food Sci. Biotechnol. 21: 661-668.

Thakur MP (2014). Present atatus and future prospects of tropical mushroom cultivation in India: a review. Indian Phytopath. 67: 113-125.

Turkoglu A, Duru ME, Mercan N, Kivrak I and Gezer K (2007). Antioxidant and antimicrobial activities of Laetiporus sulphureus (Bull.) Murrill. Food Chem. 101: 267-273.

Visioli F, Bellomo G and Galli C (1998). Free radical-scavenging properties of olive oil polyphenols. Biochem. Biophy. Res. Comm. 247: 60-64.

Woisk, RG and Salatino A (1998). Analysis of propolis: some parameters and procedures for chemical quality control. J. Apic. Res. 37: 99-105.

Zhou CX, Kong LD, Ye WC, Cheng CHK and Tan RX (2001). Inhibition of xanthine and monoamine oxidases by stillbenoids from Veratrum taliense. Plant. Med. 6: 158-161. 